\title{
Community Networks as lead users in online public services design
}

\author{
Fiorella de Cindio \\ fiorella.decindio@unimi.it \\ Laura Anna Ripamonti \\ ripamonti@dico.unimi.it \\ Cristian Peraboni \\ peraboni@dico.unimi.it
}

D.I.Co. Universita degli Studi di Milano - Italy

\section{Introduction}

Computer professionals are accustomed to conceptualizing the people who use the applications they develop as users. Unfortunately, too often this implicitly means that a passive role is thus being assigned. Research fields within computer science such as Human-Computer Interaction (HCI) and Participatory Design (PD) suggest giving much more relevance to people in the design process of computer-based systems.

The business world shows a similar attitude, people are no longer considered as passive consumers of products or services, but become a fundamental asset: companies look at customers needs and remarks to improve existing products and conceive innovative ones. However recent development in managerial approach to product/service innovation took a step forward: as we shall discuss in section 1.2, they recognize that customers contribution to innovation is even more significant and effective when they cooperates within innovation communities.

This matches with the outcomes of our own research in the area of community networks, digital cities, egovernment services and e-democracy. In the network society, as well as in the traditional one, people are owner of a fundamental sovereignty right which should allow them to play an active role in shaping their working and social life. However this role cannot be played in isolation: people have to overcome an individual perspective and act as communities: an individual remark may be wrong, a single protest may be biased, while, on the contrary, a community which converges over a shared understanding is a precious asset for designing computer-based systems and online services. The net makes this change feasible and both the private and the public sector can effectively exploit these new perspectives. However, if we focus on online public services, community networks also provide a context which collect people focused on the amelioration of civic life through the use of ICT and computer mediated communication.

This suggested us the idea that citizens' online communities can be seen as a mean for supporting the design of effective interactive online public services.

To support this vision, in this paper we will firstly (section 1) borrow from the above mentioned disciplinary fields concepts and ideas, empirically supported, in section 2, by two case studies. On this basis, in section 3 we abstract from them to sketch a prospective approach to innovative online public service design.

\subsection{A role for users in system design}

Participatory Design of computer-based systems, as we know it now, comes from a quite long tradition which can be quickly summarized by recalling the work of two key persons. The first one is Enid Mumford who, in the 1960s, introduced the socio-technical approach to work organization developed at the Tavistock Institute into the design and implementation of information systems. At that time, the computer-based system designers' attitude was to develop software solutions according to their understanding of what people are supposed to do with computer-based applications. This approach led to many unsuccessful experiences and Enid Mumford' groundbreaking work (Mumford, 1983) highlighted that, to avoid these failures - as well as for ethical reasons - it is necessary to involve workers in the redesign of their work.

The second key person is Kristen Nygaard, the computer-scientist co-inventor of SIMULA67, the first running object-oriented programming language, who was the inspiring promoter of an international conference held - at the 
beginning of the 1980s - under the auspices of the International Federation for Information Processing (IFIP) that focused the discussion on the theme "system design for, with and by the users" (Briefs, Ciborra \& Schneider, 1983; Nygaard, 1983). These three prepositions identify three layers of users involvement: the first one reflects Enid Mumford achievements: systems have to be designed for the users, taking into account their needs and perspectives, as any system designer or software developer nowadays should well know. The second layer makes a step further and consists in involving users as actors of the design phase, while the third one is when the system is conceived and designed by users themselves, with computer professionals playing as consultants and enablers.

PD evolved over the years (e.g. see Schuler \& Namioka, 1993; Blomberg \& Kensing, 1998). The Proceedings of the Biannual Participatory Design Conference organized by Computer Professionals for Social Responsibility (www.cpsr.org) track this development and present several success stories. However, in spite of its strong stress on the active involvement of people, PD contained the seed of a contradiction: it did not completely succeed in deterring attention from the idea of user - that intrinsically implies a passive role - and, as a matter of fact, this term still occurs frequently in PD literature.

Beside PD, other approaches flourished within computer science, showing a similar strong interest for the design phase of products and services and emphasising attention on the "customers": Human-Computer Interaction (HCI) and Interaction Design (ID). While HCI is about the design of ICT-based products and services only, ID covers - with a more exhaustive approach - any type of human artefacts. Both are focused on the user point of view, considering both usability and user experience issues (Preece, Rogers \& Sharp, 2002). Again, like in the PD approach, the main actor is a user, but now with a different stress: Interaction Design aims at discovering new ways of supporting people using technology, and Winograd (1997) defines it as "the design of spaces for human communication and interaction".

While all these approaches well define how users should be involved in the design processes, they are weaker in driving the selection of representative samples of users. In spite of their inspiring principles, these approaches seem to underestimate the fact that users samples selected by applying statistical criteria are not always satisfying when the members of these samples are expected to be active actors in the innovation design process, as they are not necessarily committed into the role.

We think that this limit could be, at least partially, overcome by borrowing ideas from managerial studies focusing on the innovation processes started by users.

\subsection{Designing products and services: lead users and innovation communities}

Well-known theories in the field of innovation processes describe in detail how users can become sources of innovation in product and processes, and demonstrate that all "user-innovators" share a set of well-defined common attributes. This characterization can be adopted to select highly committed and effectively skilled users to be involved in the design processes, sharpening and optimizing their outcomes.

Von Hippel extensive works about the sources of innovation (von Hippel, 2005, 2002, 1988) provide fruitful elements to sketch the above mentioned attributes. The seed of his theories lays in the observation that often the most successful product or service innovations are conceived not by producers, but by users (being them individuals or companies). This claim is supported by a substantial amount of empirical evidence, although it is intuitive that users choose successful innovative paths for specific products/services since they are the best knower of their real needs and the only to benefit directly from the innovations introduced (while innovations and improvements might not necessarily be cost-effective for companies).

Von Hippel underlines that not every user is endowed with the innovative ability, but that it is possible to define the attributes of those he calls the "lead users", i.e., the particular set of users really involved in the product/service innovative process. According to him, lead users show two special characteristics: "they are ahead of the majority of users in their populations with respect to an important market trend, and they expect to gain relatively high benefits from a solution to the needs they have encountered there" (von Hippel, 2005, p.4).

Therefore, lead users can be a key to a successful involvement of users in design processes, since they can be considered effective proxies of the behaviour of the large mass of "everymen" expected to adopt the product/service in the short term future. Their involvement could become crucial to foreseeing - especially in the design, prototyping and testing phases - needs and expectations that the product/service under development should match in the medium term.

Von Hippel investigates also beyond the mere individual attitude towards innovation and unveils how common and effective the direct, informal, user-to-user cooperation can be in organizing the often widely distributed innovation process among lead users (as it is the case, e.g., of Free/Open Source software development). This cooperation tends to give rise to what he calls "innovation communities", that create value as they enrich the social capital. This is no novelty, since the study of communities as knowledge creation environments is an hot topic in a variety of disciplinary fields, such as: sociology (Bender \& Kruger, 1982), marketing (Cova, 2003), knowledge management (McDermott, 1999, Wenger, McDermott \& Snyder, 2002), product innovation (Davenport \& Beck, 2001), etc.

In particular von Hippel adopts Wellman's definition of community (Wellman, Boase \& Chen, 2002) to define 
"innovation communities as meaning nodes consisting of individuals or firms interconnected by information transfer links which may involve face-to-face, electronic, or other communication. These can, but need not, exist within the boundaries of a membership group. They often do, but need not, incorporate the qualities of communities for participants, where "communities" is defined as meaning "networks of interpersonal ties that provide sociability, support, information, a sense of belonging, and a social identity" (von Hippel, 2005, p.96).

In most cases the innovation is created by specific communities for themselves: the "glue" for the skateboard community described in (von Hippel, 2005) is "improving skateboards". The same somehow held at the beginning for the Free/Open Source software communities: Linux was created because software developers needed a free and better operating system; the Apache software development started by the need of a web server, PHP-Nuke (among the others) from the demand of a CMS (Content Management System), and so on. However the resulting innovation widely overcomes the boundaries of the developers communities and provides advantages for a substantial mass of software users.

We dare say that it is possible to effectively push forward this approach, i.e., to rely upon the experience, the knowledge and the relationships collected within Community Networks to improve the design of innovative online public services.

\subsection{Community Networks and online public service design}

The streams of research discussed in the previous paragraphs suggested us that community networks can be seen as a lead users to be involved in the PD of innovative online public services to be then used by significant numbers of generic citizens. Actually, the distinguished attributes of a community network well fit von Hippel's definition of lead users and innovation communities if one considers "public affairs" - which are the specific area of interest of community networks - as the specific "market" and the design of online public services as the target innovation.

In fact, on the one hand, we notice that the members of a community network - that can be seen as an online community focused on public affairs (Schuler, 2000) - are individuals interested in improving the urban life by the appropriate use of online public services, quite familiar with the use of online applications and used to share, compare and discuss among them experiences done offline as well as online. They can therefore well anticipate the majority of the population in the use of online public services (e-participation, e-government, e-democracy) and may provide useful feedback from their early use. This is to say that individuals (or at least a subset of them) belonging to a community network possess the attributes of lead users.

On the other hand, we notice that the notion of innovation community proposed by von Hippel well fits with the kind of links, ties and relationships which take place, both on and off line, among the members of a community network.

Considering community networks as a lead users to be involved in the PD of innovative online public services is particularly relevant to let these new services be actually used by citizens. In fact, as Preece, Rogers \& Sharp (2002, p.173) underline: "introducing something new into people's lives [...] requires a culture change in the target user population", and when Internet services are involved "it is always useful to start by understanding similar behaviour that is already established". Foreseeing the requests and acceptance of a new online service in subsequent years by the large mass of undistinguished and heterogeneous ordinary citizens is not at all an easy matter; hence, analysing community network members response could be helpful to predict people's behaviour.

In the next section, by discussing two case studies, we provide empirical support to the conjecture that community networks can be seen as a lead users to be involved in the PD of innovative online public services.

\section{Community networks as lead users and innovation communities: two case studies}

The first case study concerns the involvement of two community networks - OYK and RCM - in a European project on e-vote, while the second the framework of cooperation between RCM and the Province of Milan.

OYK (Oppiva Ylä-Karjala) is a community network based in the Upper North Karelia (the eastern forest periphery) region of Finland, consisting of three neighboring municipalities with a total area of $4500 \mathrm{~km}^{2}$ and a population of about 20,000 inhabitants (5078 of whom are subscribers of OYK). OYK was born in 2000 from the Learning Upper North Karelia European project, aimed at improving ICT skills of people living in sparsely populated and declining areas.

RCM stands for Rete Civica di Milano (Italy) and is a community network based in Milan (located in Lombardy, the northern most developed Italian region, with a population of 1,200,00 inhabitants, 20,000 of whom are RCM subscribers and 3500 of them are very active members). RCM was started in 1994 as a project of the Community Informatics Laboratory of Università degli Studi di Milano, and since 1998 is a Participatory Foundation whose charter members are the Lombardy Region, the Milan Chamber of Commerce, the Province of Milan and the University of Milan (De Cindio, 2004). 
These two community networks provide experimental support to idea that community members can anticipate the behaviour of ordinary people while using new online public service. In neither project was this idea stated clearly from the beginning: it emerged naturally when everybody involved in the projects was forced to recognise the pivotal role that community networks members were playing during the lifecycle of both projects.

\subsection{TruE-vote: assessing people's acceptance of an e-voting system}

The TruE-vote project had been funded by the European Union and has been developed by a consortium composed by: two Universities, three private companies, two municipalities, two community networks and a regional trade union, from five European countries (Italy, France, United Kingdom, Finland and The Netherlands). It was aimed at developing an Internet voting system based on a Public Key Infrastructure (PKI) and testing its use in extensive field experiments. It included an accurate analysis of users' opinions and needs, the design and implementation of a secure voting protocol (Bruschi, Poletti \& Rosti, 2002), and field experiments in five different contexts: two municipalities (Orsay, France and Newham, UK), two communities - RCM, Italy and OYK, Finland - and a regional trade union (CGIL Lombardia, Italy) (van den Besselaar et al., 2003). In the following analysis we will leave aside CGIL, since it is a non-profit "private" subject, thus not directly comparable to the community networks or the Municipalities in representing the ordinary citizen faced with innovative online services.

During the project lifecycle, the role of the two community networks - RCM and OYK - was revealed as far more rich in potential than what one could have foreseen. Members of both the online communities adhered actively to the project, collaborating effectively to the definition of the requirements and features of the e-voting system. On the contrary, the involvement of the citizens of Orsay and Newham (as well as of the trade union members) basically failed. This has been clear from the very first phases of the TruE-vote project, when several focus groups (Morgan, 1988) were organized to collect people's expectations, concerns, doubts, etc. on e-voting, in order to define guidelines for software developers. And it became clearer in the following phases, due to the different types of contributions the community networks offered to TruE-vote. Basically the benefits they produced during the different project phases can be summed up as follows:

- Definition of system requirements: 14 focus groups were set-up, 8 of which were carried on within the online communities ( 5 in RCM and 3 in OYK). The outcomes of the discussion held in RCM and OYK had been by far the most useful and effective for the project. This was the opinion of both the developers, who got several remarks and suggestions helpful for the system design, especially the user interface, and of the social scientists partners of the project, who were in charge of assessing e-voting in general - and the specific software in particular - from a user perspective (Oosteneen and van den Besselaar, 2004). This greater involvement and capability of effectively contributing to the project seemed to be due to the stronger commitment and the superior technical skills and practical knowledge of the communities' members, that allowed them to envisage the potential problems and discuss the possible solutions facing with quite technical issues.

- Testing of the voting application:

- Beta-testing: when the unforeseen necessity of setting up a beta-tester group arose, software developers explicitly asked to involve only community members ( 80 people selected among RCM volunteers), since they were seen as more active, reliable and skilled.

- Suggestion for improvements and bug fixing: both RCM and OYK members were very active in reporting technical problems and bugs - and in suggesting possible solutions - to software developers. RCM members alone, on these issues, produced 427 emails in a public forum plus 1016 emails sent to a private address (unfortunately no similar data had been collected for OYK).

- Voting sessions organization: between December 2002 and March 2003 each demonstrator partner performed three voting sessions. Eligible voters got a smart card containing their digital signature. Votes could be cast either from a kiosk or from a PC (at home or at work) equipped with a smart card reader provided by the project organization. Obviously using the PC required a certain amount of technical skills: voters had to install the smart-card reader and the voting software application. This was not so trivial and was further complicated by the fact that the voting application was still a prototype. Because of these difficulties, Orsay and Newham decided to adopt only kiosks, unlike RCM and OYK that chose to use PCs. Also, RCM and OYK participation rate was higher, and decreased quite little in percentage along the three different voting sessions. The community networks proactive cooperation has been relevant under different perspectives:

- Support of the community: from joint analysis of voting experiments and feedback received from the voters it emerged that the special appeal of using a new technology decreases significantly among people not used to digital mediated interaction (in this case: voters not belonging to a community network). This is partially due to computer illiteracy (in the case of Newham) and to technical and/or usability problems (van den Besselaar et al., 2003). Nevertheless data suggest that RCM and OYK voters were supported by the cooperative community environment while facing technical problems. These voters were thus able to overcome difficulties thanks to the - trusted - help of other community 
members. This aptitude is not easily achievable outside a community (e.g. among "anonymous" citizens of a large municipality): for example in several cases (both in RCM and OYK) a small group of community members arranged their PCs like a "kiosk", thus enabling other members - who were experiencing technical difficulties - to cast their vote.

- Self-organization: the logistic organization of the voting experiments had been quite difficult in the two municipalities, while a curious phenomenon occurred in the two community networks. Since the mailing of smart card readers was experiencing difficulties and delays, both RCM and OYK made their minds up to organize autonomously several kiosks for voters still unequipped with smart card readers. In OYK a kiosk was set up even in the Mayor's office, while RCM organized a kiosk in the offices of Province of Milan, for the Public Body employees.

- Voting sessions assessment: after the end of the voting experiments, the voters were asked to answer to an online survey. Again, the two community networks surprised the whole project consortium with a response rate of about the $100 \%$, while this wasn't the case with Orsay and Newham. In fact, to investigate the use and effects of Internet voting, the sociologists partners of the TruE-vote project, could use only of the questionnaires collected by the two community networks (Oosteneen and van den Besselaar, 2004).

If we dig deeper into the organization of the TruE-vote voting sessions, we discover other intriguing hints of the relevance of involving online communities in the design of innovative online public services.

Orsay, thanks to its quite small dimensions (more or less 16,500 people, among whom a large number of students and researchers), the high academic, scientific and technical concentration on its territory, and the strong commitment of the Municipality - could afford to try involving all its eligible voters in the e-voting experiment. Every citizen in the electoral roll got an official letter from the Municipality, inviting her to participate to the voting pilots. In Newham (a London borough with a high rate of poverty and more or less 230,000 inhabitants) the Municipality chose to restrict the experiment to the residents of a new Estate. All the registered and active members of the two community networks were invited to participate, moreover a small group of new members signed up to RCM and OYK precisely with the purpose of participating to the experiment. Table 1 summarizes the participation rates of the demonstrators, highlighting the gap among voters belonging to a community (RCM and OYK) with respect to "individual" citizens (Orsay and Newham). The much better performance in turnout is so evident that it does not need further comments. The higher registration rate of the two community networks becomes more significant than the figures state if one takes into account that in Newham the target population was resident in the same estate and therefore quite easily reachable by the project facilitators (paid by the Newham Municipality) who succeeded in registering to the voting experiment the $6,8 \%$ of the target population; but this quite good result was no at all confirmed by the people participation to the voting experiment, as the very low turnout rate shows. In Orsay the good percentage of registration was reached thanks to a massive campaigning by the Municipality who sent an official letter to all the citizens. On the contrary, the two community networks did the recruiting entirely online without any support by the local government. Therefore, their apparently not so different registration rate becomes much more significant, and it is actually confirmed by the average turnout, in both cases over the $50 \%$.

Table 1 - Participation rates among the demonstrators of Tru-Evote project

\begin{tabular}{|c|c|c|c|c|}
\hline & $\mathrm{RCM}$ & OYK & Orsay & Newham \\
\hline Members/citizens (tot.) & 3500 & 5078 & 16500 & 1400 \\
\hline Registered voters ${ }^{1}$ & 303 & 396 & 925 & 96 \\
\hline Registration rate $^{2}(\%)$ & 8.6 & 7.3 & 5.6 & 6.8 \\
\hline Turnout - average ${ }^{3}(\%)$ & 60 & 56.3 & 39.3 & 10 \\
\hline \multicolumn{5}{|c|}{${ }^{1}$ Number of volunteers actually involved in the voting experiments } \\
\hline
\end{tabular}


These data can be explained by considering the goals and motivations for participating in the voting pilots declared by each demonstrator organization. Both Orsay and Newham focused on tackling people's interest in political voting (they both had been involved also in other e-voting pilots), since they were looking for new means of raising the continuously decreasing turnout of voters at each election. The two community networks, instead, considered the evoting experiment a natural extension of their continuous engagement in developing innovative online services and solutions supporting the community itself and its dialogue and democratic interaction with the public bodies. It is worth noticing that both the members of RCM and of OYK periodically "vote" - for polling and for internal elections - by using ad hoc software. For this reason they had already faced issues related to secrecy, security, accountability, etc. and were strongly concerned in experimenting new, more effective, solutions.

The two community networks actually demonstrated in the project a greater commitment and a much more proactive attitude with respect to those expressed by Newham and Orsay, thus supporting the idea that they can be seen as innovation communities for the design, in this case, of a trusted e-voting application.

\subsection{Province of Milan: keeping in touch with citizens}

The Province of Milan is a local government body in between the Municipalities of the Milan metropolitan area and the Lombardy Region: it supervises and coordinates the activities of 188 municipalities. It has been among the first local government bodies in Italy perceiving the importance of the Internet as a new, interactive, communication channel with citizens.

Already in 1993 the Province of Milan had its web site. In 1995 RCM proposed to the Province - which accepted to set up several so called "Linee Dirette" (literally "Direct Lines", which in English may sound somewhat like: "Keeping in Touch"). They were the first channel the local government body offered to its citizens for dialoguing in moderated public forums with several of its offices and with the President of the Province. In the beginning only RCM members could access these services, thanks to the fact that they had subscribed a "Galateo" when they registered to the community network. The Galateo is a specialized netiquette, composed of a set of rules aimed at guaranteeing fair online behavior (De Cindio et al., 2003). Milan Province saw it as a prerequisite for guaranteeing a free discussion, since it can be used - if necessary - as an effective tool for stopping flames, insults, provocations and the like. As time went by, the Galateo had been revised and more and more refined to better suit the needs of the dialogue between citizens and the local public body. For example, very soon the necessity of specifying the answer-time to citizens' questions arose: for people used to real-time online interaction, it was quite unacceptable to wait one or more days for obtaining an answer. Unfortunately, most of them did not figure out that public employees do not work during the weekend or in the evenings (and that many employees were answering only on a volunteer basis). In the same vein, while private citizens write only under their own responsibility, public employees hold the responsibility of answering on the behalf of the institution they belong to. This implies a longer answering time, which sometimes mirrors the bureaucracy public employees are faced with when seeking appropriate information to supply to the citizens. However, thanks to the fact that the citizen questions are not sent to a private mailbox, as often happens, but to public forum, everybody has visibility of the answering delay.

The Province found this experience very useful for familiarizing with the management of online communication, and for understanding the opportunities offered by the Internet to set up new, unstructured channels for dialoguing with citizens. Its employees, too, had the opportunity to learn hands-on the online dialogue principles in a sort of "protected environment" - the community network itself.

This pivotal experience convinced the Province of the importance and of the actual possibility of managing online public dialogue with citizens. The forums, initially opened within RCM, i.e., readable and writable only by RCM subscribers, have then been linked to the official site of Province, readable and writable by anybody (see http://www.retecivica.milano.it/provincia/lineedirette.php). The fine tuning of the Galateo with the RCM members produced a set of well balanced rules of behavior and policies that since then govern conversations in these public forums. They turned out to be, over the years, well suited to manage the drawbacks and difficulties that an open communication with citizens may have, such as an online protest and campaigning against decisions taken by the Province President.

Again, this example shows that RCM members have acted as early adopters and lead users for the design and development of an online public service - in this case, an online public forum supporting public dialogue among citizens and a local authority - directly influencing its most critical aspect, namely the definition of an appropriate "communication contract" between the citizens and the Province offices. It is worth remembering that, in Italy, other experiences of online public dialogue among local bodies and their citizens had to be shut down. This happened because the involved local bodies, without the interplay with a community members, did not realized the relevance of publishing the "communication contract" with citizens, and completely lost control in the face of protests and campaigning of citizens on their website. In contrast, thanks to the test and tuning of the Galateo with RCM subscribers, no serious problem arose within the Province's "Linee Dirette" when they were opened to every citizen. This led to the great success achieved in 2004 (and repeated afterwards): the Province of Milan received the best score among the most "interactive" public web sites in the yearly placing done by CENSIS, the Italian Research Institute, which surveys since 
1997 digital cities and e-government services.

\section{A prospective approach: community network members as "everyman"}

Once accepted the idea that it is possible to rely upon the experiences, the knowledge and the relationships collected within a community network to improve the design of innovative online public services, two methodological problems arise. Firstly: to what extent a sample of today members of the online community is representative of tomorrow's ordinary users? In fact, if the composition of the population of the community network significantly diverges from the composition of target users of the online public service, the advantages deriving from involving it as innovation community could vanish or even become misleading. Secondly: is it possible to infer guidelines for driving the design of online public service in such a way that the design process can take advantage from the actual involvement of a community network?

These two issues are discussed in the next paragraphs.

\subsection{Similarities and differences between community networks' members and ordinary citizens}

Since no detailed profiling system is adopted by RCM (due to a combination of technical, social and historical reasons), it is not easy to determine how much a sample of its "typical" members is, or is not, really representative of the ordinary people. However, a survey made by CENSIS several years ago (CENSIS, Assinform, RUR, 1998) already proved that the composition (for distribution of age classes) of RCM population is more similar to that of the Italian population than that of the typical Italian Internet users. In order to confirm this point, we have compared the profile (age and literacy) of members that registered to RCM in 2003 to the profile of Internet users in 2003 and to the composition of the Italian population (see Fig.1).

RCM's member data are taken from the database of the registered users, that is fed with the data of each new subscriber. The profile of the Italian Internet users is taken from the yearly survey done by CENSIS (hence it is a "statistical" data). Finally, the composition of the Italian population is taken directly from the data collected during the last census by the Italian National Institute of Statistics (ISTAT, 2001). Since our sources are so heterogeneous, the comparison - at the moment - can be only qualitative. However, for our present aim, a qualitative comparison of the different curves is enough.

In Fig. 1 age classes of the Italian population, the Italian Internet users and RCM subscribers are compared. Notice that, while the data of the Italian population and the Italian Internet users are quite immediately comparable (Internet users data is given as percentage on the total population per age class), the data of RCM subscribers are given - for every age class - as percentage of the total of the subscribers. What can be noticed is that the curves of Internet users and RCM subscribers are quite similar - except for a peak on the 20-29 years class, while they both differ from the population curve for ages above 59 years. The peak is easily explainable, since RCM hosts several educational activities (mainly related to undergraduate courses in Informatics). Anyhow, the composition (age classes) of RCM subscribers in 2003 is similar to the one of the typical Internet user and of the population with less than 60 years. This comparison is biased by the fact that the RCM data are referred only to members that subscribed during 2003 . We think that, collecting the cumulated data (from 1994 to 2003) about the age of all the RCM members, we would obtain a distribution closer to the one that emerged from the CENSIS survey made in 1998 we mentioned above. Collecting these data will be the next step in our research.

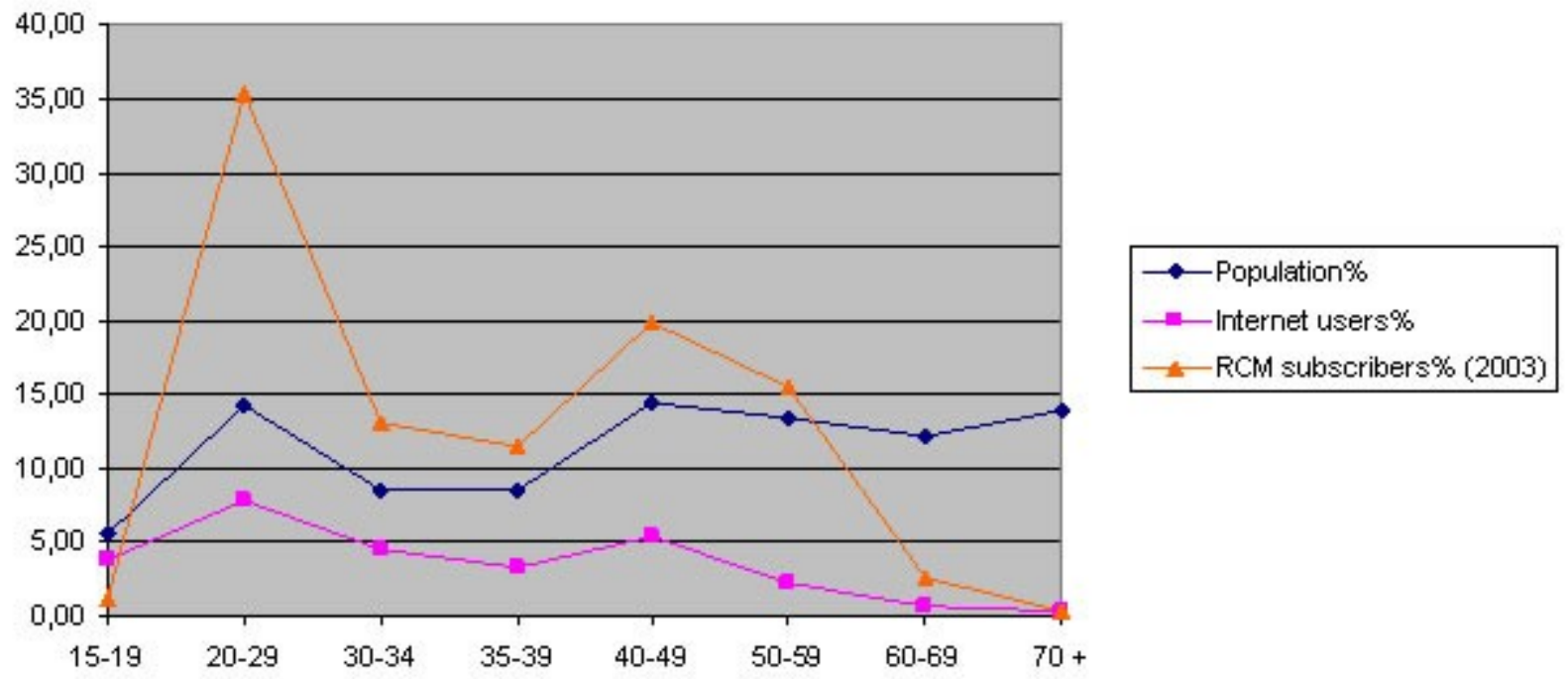

Figure 1: Comparison among RCM subscribers, Internet users and population: age classes 
In Fig. 2 we have compared the degree of formal education of the Italian population to that of the Italian Internet users and of the RCM subscribers in 2002 and 2003. The data sources are the same as for age classes in Fig.1. It is important to point out that the percentages of Internet users are calculated on the total population, while for RCM they are referred to the total of RCM subscribers. The distribution of percentages of Internet users varies sensibly along the temporal interval, while it is quite stable in RCM. Among Internet users the rate of "university degree and more" significantly increased during the period 2000 - 2003, while the same does not hold true in RCM. One possible explanation of this phenomenon is the massive diffusion - in that period - of the Internet in the business world, pushing new, better-trained and higher-educated users on the net. The largest gap between RCM's curves and the population's one is located in the lower levels. This is not surprising: people in their sixties (or more) present the highest rate of low formal education, since, in Italy, the compulsory education till the age of 14 has been introduced only during the 60 s of the last century.

In general, for the purpose of this work, we observe that the composition (for age and literacy classes) of the population registered in RCM does not diverges too much (but for the elders) from the composition of the Italian population and approximate it better then the Internet users distribution.

Moving to a more qualitative analysis, we observed that, from the online behaviour point of view, the main difference between Internet users and RCM members consists in the different way in which they use the net. While Internet users are individuals, using mainly services such as search engines, email, booking (as reported by CENSIS surveys - www.censis.it), RCM is a community of people (that is to say a social network) interested in civic and local themes, used to meet online in public forums and to approach ICT in socially innovative ways (some of them have been able to conceive, design and implement within RCM their own projects, see De Cindio, 2004), thus developing a common understanding and shared practices about civic issues. Indeed, we believe that the recent evolution of the Internet toward the so called web 2.0 (O'Reilly, 2005) is shifting the way in which generic people approach the Internet to the one typical of online communities. This makes even more relevant the role that the RCM community may have in the design of online public services.



Figure 2: Comparison between RCM subscribers and Italian population: formal education

\subsection{Blueprint for the involvement of community networks}

In order to put at work the idea of involving the members of a community network into the design and testing of innovative public service, in this section we outline an approach to online public service design inspired by the considerations discussed in $\S 1$ which abstracts from the case studies described in $\S 2$. We identify three major phases (see Fig.3), each one characterized by the different role the community network plays. 
In the first phase, when the requirements and the functionalities of the new application have to be defined, the community network members are involved as a sample of tomorrow's everyman. By participating in focus groups organized to define the system requirements as well as in testing the system prototype(s) and first release(s), they generate highly valuable feedbacks concerning: the features of the application under development; how far it matches users' needs and expectations; how much learnable and usable it is; the acceptance by users; how people diversity is taken into account; etc. This is exactly what happened in the TruE-vote project (that unfortunately stopped after the testing of the prototype of the voting system), and corresponds to the use of the "Linee Dirette" of the Province of Milan only by RCM members.

When the new service has reached a quite stable state, it may be gradually opened to people not belonging to the community network to simulate, incrementally, its use by the whole mass of citizens. In this second phase community members still supplies the major part of the feedbacks and suggestions for improvements. However, their major role is establishing a sort of friendly and helping learning environment for new users. This is precisely what happened in the Province of Milan case: when the "Linee Dirette" forums, initially reserved to RCM members, have been opened to ordinary people, they could read the messages written by the community members, learning 'by example' a fair communication style, the pattern of behavior between citizens and public employees and, last but not least, how to rely on the Galateo, when necessary. Technically, the "Linee Dirette" forums were linked from the Province web site in a not too visible way, but hosted and managed by RCM, and this was clearly perceivable by the web site visitors.

In the last phase the service is released for everyday use by any citizen. The role of community members becomes less and less relevant, although its involvement should not be underestimated. Their presence somewhat guarantees the possibility of relying, in case of need, on trusted participants. In the Province case this phase corresponds to the complete embedding of the "Linee Dirette" in its institutional web site. This means that, although they continue to be hosted on RCM servers, they are fully managed by the Province employees who act as forums moderators, completely integrated also from a "look and feel" and graphical point of view, and linked from a highly visible page. Two examples clarify the kind of weak support the community networks still supplies. Firstly, the RCM community manager is often consulted, via chat or email, by the moderators when they have to face with some non standard situation ("how can I explain to that citizens that he has to ....."; "should I approve that message that....", etc.). Secondly, when a significant protest against a decision of the Province President took place in the "Linea Diretta", several RCM members, although supporting the protest, were active in preserving the politeness of the forum.

Each one of the three phases may consists of one or more iteration, which, depending on the specific case, may also include a substantial software development (as in the TruE-vote case) or a new application of existing software (as in the case of the Province "Linee Dirette").

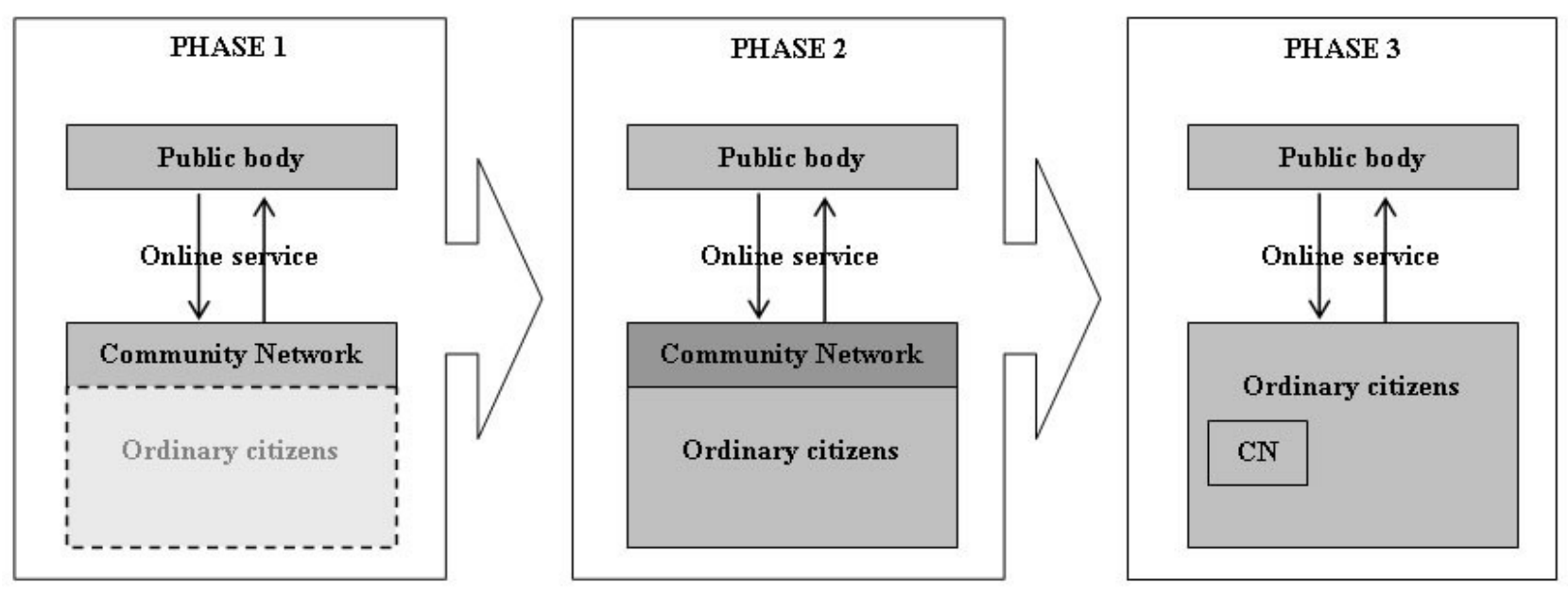

Figure 3 - Different levels of involvement of a community network in innovative online public service design and implementation

\section{Conclusions and future research}

In this work we have tackled the problem of designing innovative online public services. We maintain that community networks, i.e., online communities of citizens focused on public affaires, civic engagement and local community empowerment contain the seed of a value or asset of which a farseeing public bodies should be aware of and take advantage of. The involvement of community networks members involvement could be highly beneficial in the design and testing of innovative online public services, since they can be regarded at as the typical pioneers of innovation à la von Hippel - and thus representative of tomorrow's "everyman's" behavior.

The foreseeable beneficial effects of their involvement will impact mainly on the adherence of the online services 
to users' needs, on users' acceptance and on the reduction of the time necessary to develop the service. This will have beneficial effects also on the economics and on the "image" of the public body promoting the new service.

While the case studies presented in this paper to support our conjecture conceptualize "ex-post facto" what actually occurred in the two projects, it would be now worth applying the proposed approach from scratch in the design of new online services. This is what we are currently doing while developing a set of software tools aimed at supporting online deliberation in the framework of the project " 221 for the development of digital citizenship in Agenda 21". This project involves ten municipalities in the Lombardy Region (Mantua - the coordinator, Brescia, Como, Desenzano sul Garda, Lecco, Pavia, San Donato Milanese, Sesto San Giovanni, Vigevano, and Vimercate). In two among them a community network is active (although the two cases differ in the formal relation between the community network and the municipality) and in a third one the municipality official site hosts a lively citizens' forum. Already during the system requirement phase, we got more significant feedbacks from these three experiences then form the others (although unfortunately it was not possible for us to directly interact with the community members): indeed, a major modification in the initial system specifications came from comparing the moderation policy adopted by these different online communities. It will be interesting to observe and investigate whether or not the next phases of the e 21 project confirm the role - envisaged in this paper - that online communities of citizens may play in innovative public services design.

\section{Acknowledgement}

We wish to thank two anonymous reviewers for their helpful comments. This research has been partly carried on under the project PRIN 2006-148797 funded by the Italian Ministry of University and Research.

\section{References}

Bender, T., \& Kruger, S.M. (1982). Community and social change in America. Baltimore: Johns Hopkins University Press, 7-8.

Blomberg, J., \& Kensing, F. (1998). Participatory Design: Issues and Concerns. The Journal of Collaborative Computing, Special Issue on Participatory Design, Computer Supported Cooperative Work, 3-4, 167-185.

Briefs, U., Ciborra, C., \& Schneider, L. (1983). Systems design for, with and by the users. North-Holland.

Bruschi, D., Poletti, G., \& Rosti, E. (2002). E-vote and PKI's: a need, a bliss or a curse? In D. Gritzalis (Ed.), Secure Electronic Voting, Kluwer Academic Publishers, ISBN 1-4020-7301-1.

CENSIS, Assinform, RUR (1998). Le città digitali in Italia: rapporto 1998. Milano, Italy: FrancoAngeli (in Italian).

Cova, B. (2003). Il Marketing tribale. Milano, Italy: Ilsole24ore (in Italian).

Davenport, T.H., \& Beck, J.C. (2001). The Attention Economy: Understanding the New Currency of Business. Boston, USA: Harvard Business School Press.

De Cindio, F. (2004). The Role of Community Networks in Shaping the Network Society: Enabling People to Develop their Own Projects. In Schuler, D. \& Day, P. (Eds.) Shaping the Network Society: The New Role of Civil Society in Cyberspace, Cambridge, MA: MIT Press.

De Cindio, F., Gentile, O., Grew, P., \& Redolfi, D. (2003). Community Networks: Rules of Behavior and Social Structure. H. Sawhney (Ed.), special Issue: ICTs and Community Networking, The Information Society Journal,19(5), 395-406.

ISTAT (2001). http://dawinci.istat.it/daWinci/jsp/MD/dawinciMD.jsp (in Italian. Last visited: Jan, 10th, 2006)

McDermott, R. (1999). Why information technology inspired, but cannot deliver knowledge management. California Management Review 41, no.3: 103-117.

Morgan, D. L. (1988). Focus groups as qualitative research. Newbury Park, CA: Sage.

Mumford, E. (1983). Design Participatively. Manchester, UK: Manchester Business School.

Nygaard, K. (1983). Participation in System Development. The Task Ahead. In U. Briefs, C. Ciborra, \& L. Schneider (Eds.), Systems design for, with and by the users. North-Holland.

Oosteneen, A.M. \& van den Besselaar, P. (2004). Security as Belief: User's Perceptions on the Security of e-Voting Systems. In A. Prosser and R. Krimmer (Eds.), Electronic Voting in Europe - Technology, Law, Politics and Society, Lectures Notes in Informatics, vol. P-47, Bonn, Germany: Geellschaft fur Informatik, 73-82.

O’Reilly, T. (2005). What Is Web 2.0: Design Patterns and Business Models for the Next Generation of Software, On May 13.2007 at the URL:http://www.oreillynet.com/pub/a/oreilly/tim/news/2005/09/30/what-is-web-20.html

Preece, J., Rogers, Y., \& Sharp, H. (2002). Interaction Design: beyond human-computer interaction. US: John Wiley \& 
Sons.

Schuler, D. (2000). New Communities and New Community Networks. In M. Gurstein (Ed.) Community Informatics: Enabling Communities with Information and Communication Technologies, Hershey, PA: Idea Group Publishing.

Schuler, D., \& Namioka, A. (1993). Participatory Design: Principles and Practices, Hillsdale,NJ: Erlbaum.

van den Besselaar, P., Oosteveen, A.M., De Cindio, F. \& Ferrazzi, D. (2003). Experiments with e-voting technology: experiences and lessons. In P. Cunningham et al. (Eds.) Building the Knowledge Economy: Issues, Applications, Case Studies. IOS Press.

von Hippel, E. (1988). The sources of innovation. New York, NY, US: Oxford University Press.

von Hippel, E. (2002). Horizontal innovation networks - by and for users. Working Paper No.4366-02, MIT Sloan School of Management.

von Hippel, E. (2005). Democratizing Innovation. Cambridge, MA, US: MIT Press.

Wellman , B., Boase, J. \& Chen, W. (2002). The networked Nature of Community On and Off the Internet. Working paper, Centre for Urban and Community Studies, University of Toronto.

Wenger, E., McDermott, R., \& Snyder, W.M. (2002). Cultivating Communities of Practice. Boston, MA, US: Harvard Business School Press.

Winograd, T. (1997). From computing machinery to interaction design. In P. Denning \& R. Metcalfe (Eds.) Beyond Calculation: the Next Fifty Years of Computing. Amsterdam: Springer-Verlag, 146-162. 